\title{
The Effect of Facebook, WhatsApp, Twitter and Email on SMEs Performance: Empirical Evidence from United Arab Emirates
}

\author{
Saeed Khalifan RASHEED GHANEM and Nor Aziati Binti ABDUL HAMID
}

Faculty of Technology Management and Business

Universiti Tun Hussein Onn Malaysia

Parit Raja, Batu Pahat, Johor

Correspondence should be addressed to: Saeed Khalifan RASHEED; saeedkhalfan91@gmail.com

Received date:4 February 2020; Accepted date:10 July 2020; published date: 18 August 2020

Academic Editor: Aw Yoke Cheng

Copyright (C) 2020. Saeed Khalifan RASHEED GHANEM and Nor Aziati Binti ABDUL HAMID.

Distributed under Creative Commons Attribution 4.0 International CC-BY 4.0

\begin{abstract}
Social media marketing tools are a phenomenon that has become an important aspect of the marketing mix and revolutionized the way companies interact with their customers. It is a new field of research and literature quick scan revealed that not many studies exist on social media marketing tools on SMEs in Abu Dhabi UAE. However, the few existing studies, without scientific proof to SMEs in Abu Dhabi UAE data, have been rushing to conclude that the emergence of social media marketing tools has led to the death benefits of social media for SMEs' performance. Therefore, this research work is on the mediating effects of organizational culture on the relationship between social media marketing tools and SMEs' performance in Abu Dhabi UAE. Therefore, this research is on the effect of social media tools (i.e. Facebook, WhatsApp, Twitter and Email) on the performance of SMEs in UAE; a structural equation modelling. Data were collected from the SMEs in Abu Dhabi. The research employed quantitative approach and used questionnaires to collect relevant data from the respondents. The model was developed using SPSS and AMOS software as the research is quantitative in nature.
\end{abstract}

Keywords: Facebook, WhatsApp, Twitter, Email; National Culture, SMEs, UAE

\section{Introduction}

The usage of online marketing technologies in SMEs does not stretch out to the required level (Ahmad et al., 2019). In the study conducted by Sarah (2012) on the social media marketing in a small business, the results found that SMEs are not using social

Cite this Article as: Saeed Khalifan RASHEED GHANEM and Nor Aziati Binti ABDUL HAMID. (2020), "The Effect of Facebook, WhatsApp, Twitter and Email on SMEs Performance: Empirical Evidence from United Arab Emirates", Journal of Internet Social Networking \& Virtual Communities, Vol. 2020 (2020), Article ID 618899, DOI: $10.5171 / 2020.618899$ 
network marketing to its full potential and scope. SMEs have been struggling to follow a sequence of stages in their adoption of Internet technologies. These staged models were also termed to be ladders, postulate that businesses move in stages from basic use of the Internet as an e-mail or marketing tool to a more sophisticated use that integrates business systems and redesigns business processes (Fernando, 2005).

Online social channels offer connectivity and transparency for SMEs to gain a competitive advantage. $83 \%$ of marketers indicated that social media network is very important for their business (Nuseir, 2018). A report by Orient Planet Research found that social media channels such as Facebook, YouTube, WhatsApp and LinkedIn are increasingly being used by SMEs and have become major business enablers. The report also revealed that social media in U.A.E present themselves as an invaluable tool for SMEs due to the range of benefits that they have to offer and at a reasonable cost. The report also showed that SMEs represent 95 per cent of all local establishments, accounting for 42 per cent of the workforce and contributing around 40 per cent to Dubai's economy (Basri, 2016).

Today the penetration of social media network is huge in U.A.E. However, it is not being used for marketing purposes (AlSharji, 2018). Even though, the U.A.E is among the top countries in the world, with high percent smartphone penetration $(78 \%)$ and more social media adoption even higher than the United States (Zaidan, 2017). This shows that the UAE citizen does not make full advantage of social network especially with broad coverage wider penetration for the online user encourage them to use internet for their activities not only for connecting with friends and family member, but they can also use internet for business activates like shopping and buying and selling things.

\section{Digital contribution to Middle East economy is low compared with benchmarks Share of digital contribution to GDP, $\%$}
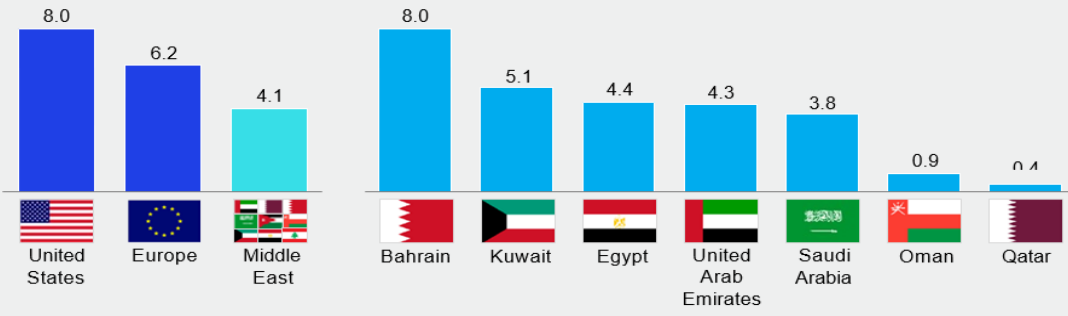

Figure 1: The digital distribution in Middle East economy

Source: James et al (2016)

In addition to that, the UAE government ranks number one in digital and Internet adoption among Middle Eastern countries and matches the digital frontier countries. Nonetheless, using social media as marketing agent for SMEs in U.A.E is not encouraging (Makki, et al., 2015). It is found that $73 \%$ of small businesses are now using social media. Furthermore, four fifths (81 percent) of these plan to further increase their social marketing efforts, and $62 \%$ of SMEs that are not currently using these channels have said that they plan to do so in the next year (Basri, 2019). Based on the survey conducted by IPSOS, of those UAE online adults polled, $63 \%$ had shopped online in the last 12 months with almost half (49\%) of this shopping both domestically and cross-border and the top three countries that UAE online shoppers opt to buy from are revealed as the United States (30\%), United Kingdom (18\%) and India (18\%). These statistics show how online shopping gives impact to the businesses locally and globally. The statistics highlighted that UAE citizens are still not 
satisfied with the quality of the e-commerce website locally whereby they prefer to shop from other countries instead of their local website. Hence, it is important to increase the economic growth specifically among SMEs in U.A.E that have interest to involve with e-commerce and social media marketing activities. The presence of SMEs in UAE economy is trivial, for example SMEs contribute around $40 \%$ to the total valueadd generated by Dubai's economy, with the trading accounted for $47 \%$ of the total value-add by SMEs; the share of Service
SMEs is around $41 \%$ and that of Manufacturing SMEs is estimated at around 13\% (Abu Bakar et al., 2019).

The consumers in U.A.E are primed and ready to lead digitally enhanced lives; businesses and governments have not fully embraced the digital opportunity yet. A recent survey revealed that just 18 percent of small and midsize enterprises (SMEs) in the United Arab Emirates have an online presence through social media network (Olanrewaju et al., 2020).

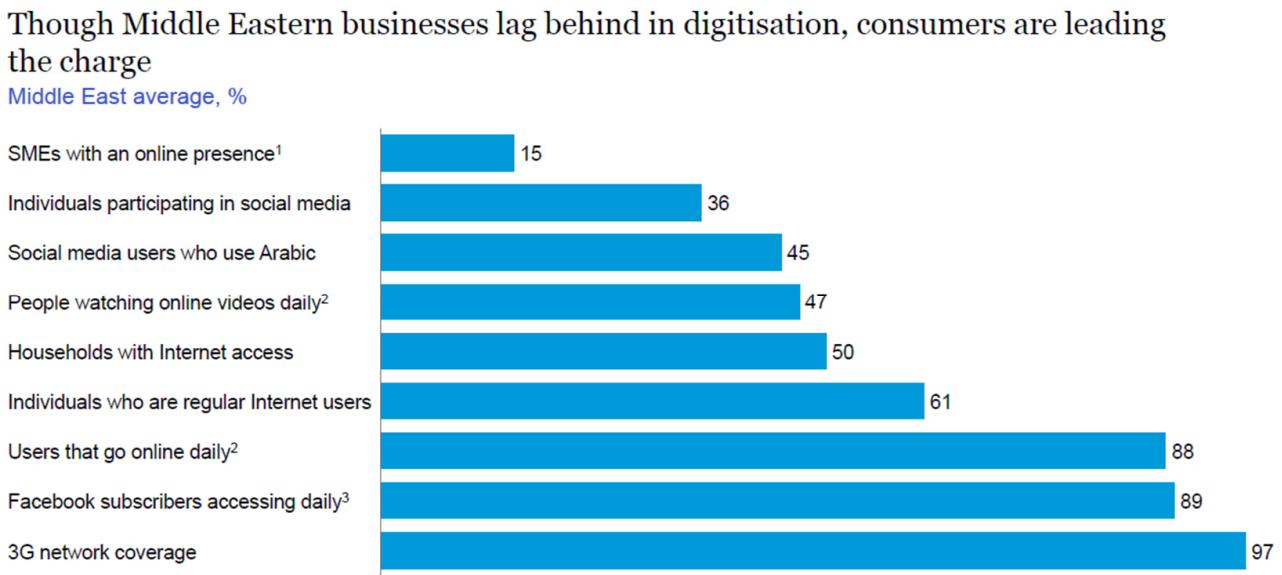

Figure 2: SMEs percentage of presence in online business

Source: Networked Readiness Index (2015)

Despite the following figure shows SMEs percentage of presence in online business. It is evident that the presence of SMEs through social media network is facing big challenges due to several obstacles, whereby 2019, projections estimate that the Middle East and Africa will have the world's highest cloud traffic growth rate at $41 \%$ (Global Cloud Index forecast, 2016). Large corporations as well as SMEs in U.A.E often struggle to drive innovation from inside the company. Today, many companies have yet to tap into social media opportunities to innovate in business and expand (Kareem, 2015). Social media adaption by firms creates a great network among businesses, customers and suppliers. However, less attention has been paid to the social media marketing values for SMEs performance (Odoom et al., 2018). Given that small and medium sized enterprises are economic engine of most of countries, previous studies mainly have focused on the adaption (Durkin, McGowan, \& McKeown, 2013; Wamba \& Carter, 2016), benefits, and barriers (Michaelidou, Siamagka, \& Christodoulides, 2011) of social media in SMEs' context. SMEs in U.A.E do not fully make the best use of the potentials and opportunities offered by online marketing. The application of mobile devices, and social media networks (SMNs) such as Facebook has revolutionalised the ecommerce adoption process in SMEs. However, research into this area is still developing and there is a dearth of knowledge on how SMEs in UAE enact and apply this phenomenon.

There is a growing body of academic literature on the use of social media marketing among SMEs. However, most of the existing studies focus on larger enterprises that have a higher propensity 
for adopting new and innovative technologies. There have been modest studies on social media marketing in the context of SMEs explicitly (Ahmed et al. 2018). It is widely known that SMEs are often less likely to use emerging technologies due to their limited capabilities, lack of resources, absence of technical expertise, unstable organization structure, small number of employees and lack of capacity (Al Tawara et al., 2017). Additionally, Karjaluoto (2015) found out that SMEs look like not utilising the social media and online tools to maximum potential marketing, and therefore SMEs are not getting any benefits or offers by these tools. This result is matched with a study conducted by Alaa (2016) in U.A.E. They found that SMEs' average sales from online marketing are $32.2 \%$ and it is "somewhat very low" due to low attitude of customers to rely on social media ads of SMEs; he found a positive correlation between sales of SMEs and the efficiency of social media marketing.

Based on the above argument, the problem statement of the current study is that SMEs in U.A.E are unable to achieve a significant increase in their sales through social media network due to several obstacles such as the weak attitude of customers to use social media ads, subjective norm of customers, information quality of ads on social media pages, and behavioral intention to use social media network as a marketing agent for ecommerce in U.A.E. This problem will be investigated in this study and suggesting the appropriate recommendations.

\section{Literature Review}

\section{Facebook}

A business could use multiple touch points of Social media and digital strategy to achieve a specific goal. Each touch point needs to be effectively used, if a company's goal is to drive an online sale to an ecommerce website. In Facebook, for instance, the use of "Like" adverts can grow fan pages with targeted consumers (Salloum, Al-Emran, Monem, \& Shaalan, 2017). One of the reasons for the high number of Facebook active users is that anyone who is at least 13 years is allowed to register as user (Robertson, \& Kee, 2017). Facebook was launched in 2004 and holds the most promise for retailers, in offering varieties of ways to reach and attract new shoppers (Chugh, \& Ruhi, 2018). As of 2011, this social networking site was reported to have 750 million active users and, as at second quarter of 2015, had 1.45 billion active users (Galati, Crescimanno, Tinervia, \& Fagnani, 2017). It is ranked as the most used social network worldwide. Also, on a daily basis, traffic to the network is on the rise (Bellucci, \& Manetti, 2017). There is ability to create a Page which serves as an extension of their online shop that can be used to connect with customers, distribute content, promote products offers, services, and brands and attract online shoppers. Facebook can also be used to advertise products and provide a link to a blog post about the business or industry to online shoppers (Assimakopoulos, Antoniadis, Kayas, \& Dvizac, 2017).

\section{WhatsApp}

Enterprises can use WhatsApp Marketing Tool to promote their business, interact with users by sending and receiving text and media files using the rich interface by requesting early access to the platform (Stone, \& Logan, 2018). This can be done by contacting the companies which provide the API integration with WhatsApp and offer their technical support to enterprises in managing the platform (Khatun, \& Al-Dhlan, 2017). Furthermore, WhatsApp has introduced WhatsApp Business app for small, medium and large-scale enterprises of all industries. This app enables enterprises to stay in touch with customers and expand their market base by effectively using the app and promoting the business irrespective of where the users reside (Dar, Ahmad, Ramzan, Khan, Ramzan, Ahmed, \& Kamal, 2017).

\section{Twitter}

Twitter was launched in 2006, and it gained a lot of popularity because it offered new options, such as micro blogging, and it was also used by some celebrities (Sinnenberg, Buttenheim, Padrez, Mancheno, Ungar, \& Merchant, 2017). It had about 200 million users as of 2011 and, as of the third quarter 
of 2015, the microblogging service averaged at 307 million monthly active users (Chawinga, 2017). Twitter is normally used to lodge complaints about a company's products or services, generate new traffic by promoting product offers, advice, suggestions and new content to a company's followers (Enli, 2017). Twitter can be used to post multiple updates about company products and services, but its real power is its ability to break down the traditional barriers between the company and its customers, by providing insight into customer opinion and allowing the company to respond proactively to customer issues (Duncombe, 2017).

\section{Email}

Email marketing messages can be customized for different customers and provide contents and promotions that are consistent with their profile. Customers acquire what they want and thus they obtain better view about what each section of current business will respond (Davis, 2018). A company can continue to send more relevant E-mails. By E-mail marketing, a company can easily find the number of Emails sent, number of E-mails that have been opened and those who have opened up, the number of people who are not registered, and click rate (which includes the link been effective and who clicked on it). Creating a marketing message via E-mail is almost as easy as writing an E-mail. E-mail marketing has a tool called an "autoresponder". For example, if a company wants to send a campaign message to their recipients on special days you just create the messages and schedule them (Hall, 2018).

\section{National Culture}

National culture defines as the collective mental programming of the people in a national "context". Through an empirical study examining about 10,000 directors, executives and managers in over 50 nations, Hofstede developed a quantitative classification scheme for measuring differences and similarities between national cultures (Hofstede, 1980). Thus, in the last few decades there has been an increase in interest in this subject, and social media in recent years carried out a considerable amount of research related to cultural dimensions and attitudes. Research has demonstrated the importance of addressing this issue in order to improve business performance. Therefore, in this paper the researcher used national culture to investigate its indirect effect on the relationship between social media tools and SMEs' performance.

\section{Methodology}

The study used quantitative approach to achieve the research objectives. The use of quantitative methodology provides a concrete manifestation of the findings on an actual setting. In the same light, the use of this type of research allows the researcher to measure the parameters held in the objective of this research. (Benz, 2011).

The collection of data for analysis was conducted through questionnaires as the main tools for collecting data. Quantitative research based on the statistics was used to evaluate the impact of social media marketing and e-commerce on the performance of SMEs in UAE. Also, SPSS and AMOS software were employed to analyse the data collected from the respondents.

\section{Result}

\section{Demographic Information}

Table 1 shows the firm information provided by the respondents. About 40 percent of the respondents indicated that their firms had 6-20 employees while a slightly above 10 percent indicated that their firm had 101-250 employees. Only 2 respondents indicated that their firm had more than 251 employees. Exactly 29 percent indicated that their firm had 21 to 100 employees while the remaining 19 percent showed that their firms' employee capacity was between 1 to 5 employees.

Information on the type of activities undertaken by the firm indicated that the majority were in the service sector (42.4\%). This was followed by manufacturing (25.3 $\%)$, research and development (19.6\%). The remaining firms either engage in 
wholesale, retailing or distribution as the case may be.

Regarding the number of years the firm spends doing business, about 47 percent indicated that they spent more than 15 years in business, 44.1 percent spent 7 to 15 years while the remaining indicated that they spent between 1 to 7 years in business.

Considering the position of the respondents, 42.4 percent indicated that they were owner managers, about 40 percent indicated that they were managers while about 13 percent mentioned that they were supervisors. The remaining 5 percent indicated that they were employees.

On sectorial distribution of the respondents' firm, about 67 percent indicated that they were in private sector while the remaining 33 percent were in public sector. Regarding the social media use, the analysis revealed that all the respondents indicated that they use social media.

More than 50 percent of the respondents indicated that they use social media for networking for more than 5 years. Another 30 percent of the respondents indicated that they had been using social media for networking for about 3-4 years while 8.2 percent indicated that they had been using social media for networking for the period of 1-2 years. Less than 3 percent indicated that they spend less than a month using social media for networking.

When asked about the effect of online networking, more than the three-quarter of the respondents indicated that it somehow has effect on face to face communication. Some 16 percent believed that online networking could replace face to face communication while 6 percent of the respondents believed that online networking had no effect on face to face communication.

The majority of the respondents agreed that social media are important (38.8\%) while exactly 32.2 percent strongly agreed that social media are important. More than onequarter (29\%) had a fair opinion about the importance of social media.

Table 1: Demographic characteristics

\begin{tabular}{|l|c|c|}
\hline & Frequency & Percent \\
\hline & Number of employees & \\
\hline $1-5$ & 47 & 19.2 \\
\hline $6-20$ & 97 & 39.6 \\
\hline $21-100$ & 71 & 29.0 \\
\hline $101-250$ & 28 & 11.4 \\
\hline 251 and above & 2 & .8 \\
\hline Total & 245 & 100.0 \\
\hline & & 25.3 \\
\hline Manufacturing & Firm Type & 42.4 \\
\hline Service & 104 & 19.6 \\
\hline Research \& Development & 48 & 8.6 \\
\hline Wholesale & 21 & 2.4 \\
\hline Retailing & 6 & 1.6 \\
\hline Distribution & 4 & 100.0 \\
\hline Total & 245 & \\
\hline & & 2.0 \\
\hline Less than 3 years & Years in business & 7.3 \\
\hline 3-7 years & 5 & 44.1 \\
\hline 7-15 years & 18 & 46.5 \\
\hline More than 15 years & 108 & \\
\hline & 114 & \\
\hline
\end{tabular}

Saeed Khalifan RASHEED GHANEM and Nor Aziati Binti ABDUL HAMID (2020), Journal of Internet Social Networking \& Virtual Communities, DOI: 10.5171/2020.618899 


\begin{tabular}{|c|c|c|}
\hline Total & 245 & 100.0 \\
\hline & Job Position & \\
\hline Owner manager & 104 & 42.4 \\
\hline Manager & 97 & 39.6 \\
\hline Supervisor & 31 & 12.7 \\
\hline Employee & 13 & 5.3 \\
\hline \multirow[t]{2}{*}{ Total } & 245 & 100.0 \\
\hline & Sector & \\
\hline Private & 163 & 66.5 \\
\hline Public & 82 & 33.5 \\
\hline \multirow[t]{2}{*}{ Total } & 245 & 100.0 \\
\hline & Social media use & \\
\hline \multirow[t]{2}{*}{ Yes } & 245 & 100.0 \\
\hline & $\begin{array}{l}\text { Years of social media use for } \\
\text { networking }\end{array}$ & \\
\hline Less than a month & 7 & 2.9 \\
\hline $1-2$ years & 20 & 8.2 \\
\hline $3-4$ years & 74 & 30.2 \\
\hline More than 5 years & 144 & 58.8 \\
\hline \multirow[t]{2}{*}{ Total } & 245 & 100.0 \\
\hline & Effects of online networking & \\
\hline $\begin{array}{l}\text { Does not have any effect on face to } \\
\text { face communication }\end{array}$ & 15 & 6.1 \\
\hline $\begin{array}{l}\text { Somewhat has an effect on face to } \\
\text { face communication }\end{array}$ & 190 & 77.6 \\
\hline $\begin{array}{l}\text { Replaces face to face } \\
\text { communication }\end{array}$ & 40 & 16.3 \\
\hline \multirow[t]{2}{*}{ Total } & 245 & 100.0 \\
\hline & Importance of social media & \\
\hline Strongly agree & 79 & 32.2 \\
\hline Agree & 95 & 38.8 \\
\hline Fair & 71 & 29.0 \\
\hline Total & 245 & 100.0 \\
\hline
\end{tabular}

After explaining the demography of the respondents above and also achieving the validity and model fitness of the individual latent variables, there is a need to evaluate the validity and overall model fitness. The reliability and validity of the entire measurement model was assessed by running CFA involving the entire constructs in the research. The purpose was to establish the convergent and discriminant validity of the model prior to proceeding with the structural model evaluation.

\section{Convergent validity}

Convergent validity is a measure of the degree to which the items or indicators of a construct are correlated with the construct.
Gaffen and Straub (2005) defined convergent validity as the extent to which the proposed measures within the construct are strongly correlated. Convergent validity is normally established by determining the standardized factor loading, average variance extracted and construct reliability.

Hair et al (2010) stated that factor loading that is statistically significant indicates the achievement of convergent validity while indicators with factor loading of .50 and above are regarded sufficient to establish convergent validity. Convergent validity is also assessed using the Bentler-Bonett coefficient (NFI). Recommended threshold for convergent validity using the NFI index is .90 (Hair, et al, 2010; Kline, 2011; Byrne, 
2010). In this research, the convergent validity of the measurement model was assessed using the standardized factor loading and the NFI criteria. Table 2 shows the standardized factor loading and the NFIs of the individual latent constructs in the research. As shown in the table, the entire individual measurement models achieved convergent validity.

Table 2: Convergent validity measures of final measurement models

\begin{tabular}{|c|c|c|c|c|c|}
\hline \multirow[b]{2}{*}{$\mathbf{S} / \mathbf{N}$} & \multirow[b]{2}{*}{ Construct } & \multirow{2}{*}{$\begin{array}{l}\text { Residual } \\
\text { items } \\
\text { number }\end{array}$} & \multicolumn{2}{|c|}{ Factor loading } & \multirow{2}{*}{$\begin{array}{l}\text { NFI } \\
\text { Index }\end{array}$} \\
\hline & & & $\begin{array}{c}\text { Lowest } \\
\text { FL }\end{array}$ & $\begin{array}{c}\text { Highest } \\
\text { FL }\end{array}$ & \\
\hline 1 & Marketing & 5 & .727 & .946 & .990 \\
\hline 2 & Time & 6 & .517 & .899 & .972 \\
\hline 3 & $\begin{array}{l}\text { Human } \\
\text { resource }\end{array}$ & 6 & .547 & .789 & .967 \\
\hline 4 & Finance & 7 & .623 & .783 & .957 \\
\hline 5 & Flexibility & 6 & .518 & .806 & .968 \\
\hline 6 & Facebook & 6 & .583 & .680 & .947 \\
\hline 7 & WhatsApp & 5 & .717 & .922 & .991 \\
\hline 8 & Twitter & 5 & .720 & .796 & .984 \\
\hline 9 & Email & 5 & .574 & .822 & .975 \\
\hline 10 & $\begin{array}{l}\text { National } \\
\text { culture }\end{array}$ & 7 & .518 & .743 & .964 \\
\hline
\end{tabular}

\section{Discriminant validity}

Hair et al., (2014) described discriminant validity as the degree to which a construct is distinct from other constructs in the model. Fornell and Larcker (1986) suggested that the square of the correlation between two constructs should be less than their corresponding average variance extracted (AVE). Discriminant validity was examined by comparing the squared correlation between constructs with the average variance extracted of the individual constructs (Hair, et al. 2014). Table 3 shows the AVE of each construct at the diagonal while the off-diagonal values represent the correlation coefficients between the constructs. Based on the recommended threshold, all the AVEs are greater than .50 and each AVE value is higher than any correlation with other constructs, hence indicating the achievement of discriminant validity.

\section{Table 3: Discriminant validity}

\begin{tabular}{|l|l|l|l|l|l|l|l|l|l|l|}
\hline & MKT & TM & HMR & FIN & FLX & FB & WA & TW & EM & NC \\
\hline Marketing &. $\mathbf{7 7 9}$ & & & & & & & & & \\
\hline Time & .046 &. $\mathbf{5 6 6}$ & & & & & & & & \\
\hline Human resource & .050 & .029 &. $\mathbf{6 6 0}$ & & & & & & & \\
\hline Finance & .086 & .028 & .500 &. $\mathbf{5 1 4}$ & & & & & & \\
\hline Flexibility & .049 & .051 & .091 & .038 &. $\mathbf{7 2 6}$ & & & & & \\
\hline Facebook & .112 & .071 & .005 & .080 & .010 & $\mathbf{. 6 4 7}$ & & & & \\
\hline WhatsApp & .036 & .046 & .025 & .044 & .052 & .015 & $\mathbf{. 6 7 3}$ & & & \\
\hline Twitter & .037 & .142 & .066 & .003 & .044 & .004 & .038 & $\mathbf{. 5 9 0}$ & & \\
\hline Email & .138 & .162 & .127 & .006 & .072 & .072 & .028 & .365 &. $\mathbf{5 2 1}$ & \\
\hline National culture & .006 & .026 & .038 & .066 & .021 & .189 & .062 & .115 & .152 &. $\mathbf{6 5 8}$ \\
\hline
\end{tabular}




\section{Multicollinearity Assessment}

Checking for multicollinearity is an important requirement when evaluating structural equation models. Pallant (2011) described multicollinearity as the presence of a strong correlation between predictor variables. Hair et al. (2010) stated that multicollinearity is a threat to the validity of multivariate analysis which could lead to potential error in hypotheses testing. Hair et al., (2010) recommended that correlations between constructs should not be greater than .90. Table 3 shows the correlations among the constructs in the research model. It is shown that the highest correlation occurred between email and twitter with a Pearson's Product Moment correlation coefficient ( $r$ ) of .365, while the lowest correlation was between national culture and marketing $\mathrm{r}=.006$. This suggests that there is absence of excessive multicollinearity.

Table 4: Correlation matrix of research constructs

\begin{tabular}{|l|l|l|l|l|l|l|l|l|l|l|}
\hline & MKT & TM & HMR & FIN & FLX & FB & WA & TW & EM & NC \\
\hline Marketing & & & & & & & & & & \\
\hline Time & .046 & & & & & & & & & \\
\hline Human resource & .050 & .029 & & & & & & & & \\
\hline Finance & .086 & .028 & .500 & & & & & & & \\
\hline Flexibility & .049 & .051 & .091 & .038 & & & & & & \\
\hline Facebook & .112 & .071 & .005 & .080 & .010 & & & & & \\
\hline WhatsApp & .036 & .046 & .025 & .044 & .052 & .015 & & & & \\
\hline Twitter & .037 & .142 & .066 & .003 & .044 & .004 & .038 & & & \\
\hline Email & .138 & .162 & .127 & .006 & .072 & .072 & .028 & .365 & & \\
\hline National culture & .006 & .026 & .038 & .066 & .021 & .189 & .062 & .115 & .152 & \\
\hline
\end{tabular}

Saeed Khalifan RASHEED GHANEM and Nor Aziati Binti ABDUL HAMID (2020), Journal of Internet Social Networking \& Virtual Communities, DOI: 10.5171/2020.618899 
Table 5: Construct validity of the overall research measurement mode

\begin{tabular}{|c|c|c|c|c|}
\hline Construct & Items & Estimate & CR & AVE \\
\hline \multirow{5}{*}{ Marketing } & mkt1 & .894 & \multirow{5}{*}{.946} & \multirow{5}{*}{.779} \\
\hline & mkt2 & .902 & & \\
\hline & mkt3 & .946 & & \\
\hline & mkt4 & .926 & & \\
\hline & mkt5 & .727 & & \\
\hline \multirow{8}{*}{ Time } & tm1 & .844 & \multirow{8}{*}{.884} & \multirow{8}{*}{.566} \\
\hline & $\mathrm{tm} 2$ & .820 & & \\
\hline & $\mathrm{tm} 3$ & Item removed & & \\
\hline & tm4 & .899 & & \\
\hline & $\mathrm{tm} 5$ & .517 & & \\
\hline & $\mathrm{tm} 6$ & .690 & & \\
\hline & $\mathrm{tm} 7$ & Item removed & & \\
\hline & $\mathrm{tm} 8$ & .680 & & \\
\hline \multirow{6}{*}{ Human resource } & $\mathrm{hmr1}$ & .628 & \multirow{6}{*}{.907} & \multirow{6}{*}{.660} \\
\hline & $\mathrm{hmr2}$ & .547 & & \\
\hline & hmr3 & .658 & & \\
\hline & $\mathrm{hmr} 4$ & .690 & & \\
\hline & hmr5 & .789 & & \\
\hline & hmr6 & .649 & & \\
\hline \multirow{7}{*}{ Finance } & fin1 & .623 & \multirow{7}{*}{.881} & \multirow{7}{*}{.514} \\
\hline & fin2 & .722 & & \\
\hline & fin3 & .706 & & \\
\hline & fin4 & .775 & & \\
\hline & fin5 & .667 & & \\
\hline & fin6 & .783 & & \\
\hline & fin7 & .731 & & \\
\hline
\end{tabular}




\begin{tabular}{|c|c|c|c|c|}
\hline \multirow{7}{*}{ Flexibility } & flx1 & .518 & \multirow{7}{*}{.923} & \multirow{7}{*}{.726} \\
\hline & flx2 & .798 & & \\
\hline & flx3 & .806 & & \\
\hline & flx 4 & .755 & & \\
\hline & flx5 & .752 & & \\
\hline & flx6 & .728 & & \\
\hline & flx7 & Item removed & & \\
\hline \multirow{6}{*}{ Facebook } & $\mathrm{fb} 1$ & .583 & \multirow{6}{*}{.903} & \multirow{6}{*}{.647} \\
\hline & $\mathrm{fb} 2$ & .629 & & \\
\hline & $\mathrm{fb} 3$ & .680 & & \\
\hline & $\mathrm{fb} 4$ & .640 & & \\
\hline & $\mathrm{fb5}$ & .677 & & \\
\hline & $\mathrm{fb} 6$ & .674 & & \\
\hline \multirow{5}{*}{ Whatsapp } & wa1 & .753 & \multirow{5}{*}{.911} & \multirow{5}{*}{.673} \\
\hline & wa2 & .717 & & \\
\hline & wa3 & .876 & & \\
\hline & wa4 & .922 & & \\
\hline & wa5 & .817 & & \\
\hline \multirow{5}{*}{ Twitter } & tw1 & .720 & \multirow{5}{*}{.878} & \multirow{5}{*}{.590} \\
\hline & tw2 & .758 & & \\
\hline & tw3 & .780 & & \\
\hline & tw4 & .796 & & \\
\hline & tw5 & .783 & & \\
\hline \multirow{6}{*}{ Email } & em1 & .597 & \multirow{6}{*}{.785} & \multirow{6}{*}{.521} \\
\hline & em2 & .822 & & \\
\hline & em3 & .574 & & \\
\hline & em4 & Item removed & & \\
\hline & em5 & .632 & & \\
\hline & em6 & .613 & & \\
\hline \multirow{8}{*}{ National culture } & nc1 & .709 & \multirow{8}{*}{.913} & \multirow{8}{*}{.658} \\
\hline & nc2 & .743 & & \\
\hline & nc3 & .670 & & \\
\hline & nc4 & .645 & & \\
\hline & $\mathrm{nc5}$ & .750 & & \\
\hline & nc6 & .518 & & \\
\hline & nc7 & .573 & & \\
\hline & nc8 & .709 & & \\
\hline
\end{tabular}

Table 5 shows the measure of construct validity for the final measurement model. The respective standardized factor loading, the composite reliability (C.R.) and the AVEs all met the desired thresholds of reliability.

\section{Structural Model Evaluation}

Once the validity of the constructs was assessed and proposed measurement model achieved and model fit was confirmed then the next step was to test the hypothesized relationships

among the constructs using structural model. In another way, when a measurement model fulfills the model fit criteria, then hypothesized relations between constructs can be confirmed

building a structural model. According to Hair et al. (2010), a structural model represents

the theory with a set of structural equations and is usually depicted with a visual diagram.

After confirming the measurement model as model fit, the hypotheses were tested by investigating the strengths of proposed relationships among its constructs. This includes

testing the hypothesised theoretical 
framework and the relationships between latent constructs. Latent constructs are unobserved variables measured by their respective items or indicators.

Endogenous and exogenous are the two types of latent variables (Kline, 2011; Hair et al., 2010). In the current research, the exogenous latent constructs were FB, WA, TW, EM and NC, while the endogenous constructs were marketing, time, human resource, finance and flexibility.

To test the proposed hypotheses, structural model was tested using all ten constructs which were used in measurement model. In measurement model, constructs were associated using two sided arrows "covariance" $(\leftrightarrow)$, whereas in structural model, constructs were associated using single sided arrow $(\rightarrow)$ which represents the "path relationship" between the constructs (Hair et al., 2010). In structural equation modeling (SEM), structural model assessment results produce estimated path coefficient, standard errors, critical ratio (C.R.) or t-values, and p-values. The t-values is the critical ratio (C.R.) achieved by dividing path coefficient by standard errors. Hypothesized relationship is considered significant when C.R. or t-value ( $>=1.96)$. Non-significant path coefficient can be considered unimportant in the model and can be eliminated from the model (Hair et al., 2010).

Figure 3 shows the first-round output of the structural model. From the figure, it is shown that while other fitness indexes were achieved, some indexes failed to meet the acceptable level. For example, all the observed factors loading and their corresponding square multiple regression meet the required thresholds of .50 and .30 respectively. In respect of the fit indexes, however, none satisfied the requirement for model fitness which was an indication that model re-specification was required.

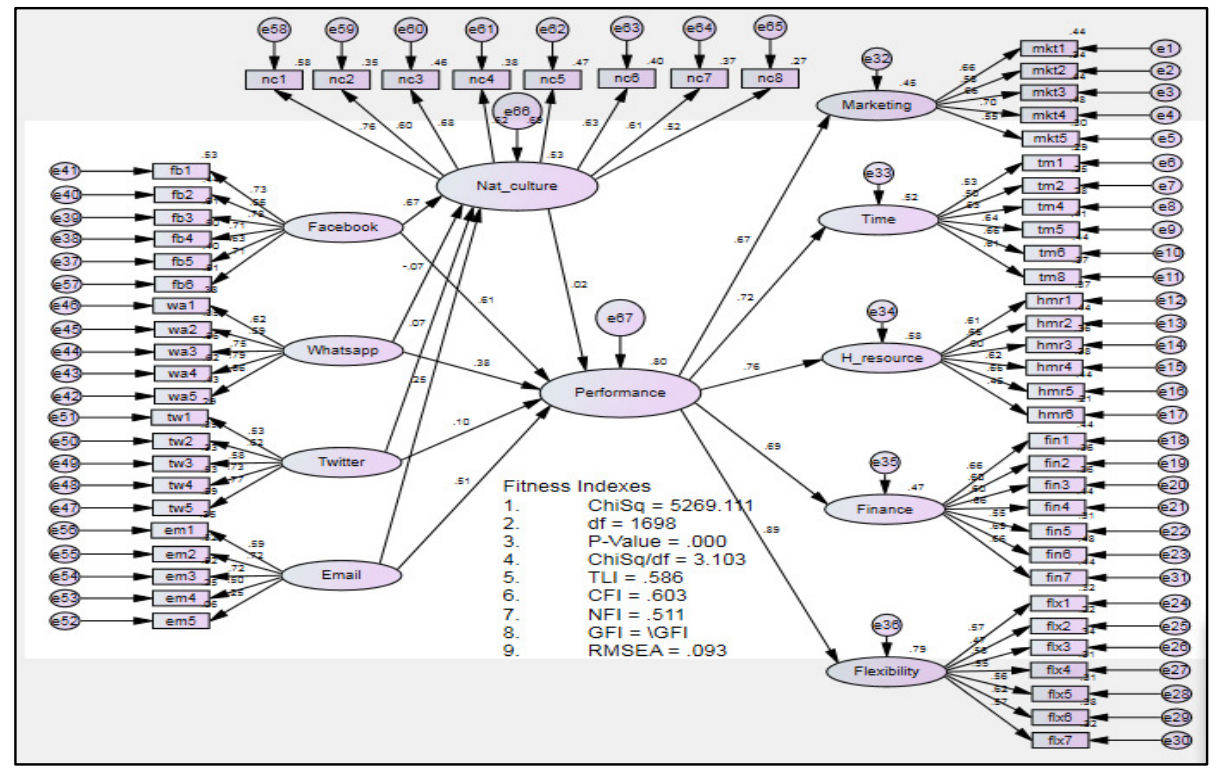

Figure 3: Initial structural model

A re-specified model is presented in Figure 4. The final structural model was achieved after a reiterative process of re-specification based on the examination of the standardized factor loading, SMCs, and other relevant fitness indices. In the process, the latent construct, twitter, had to be removed entirely from the model due to insufficient loading. Similarly, only 1 item was deleted from the latent construct (flexibility). The final model had achieved model fitness. 


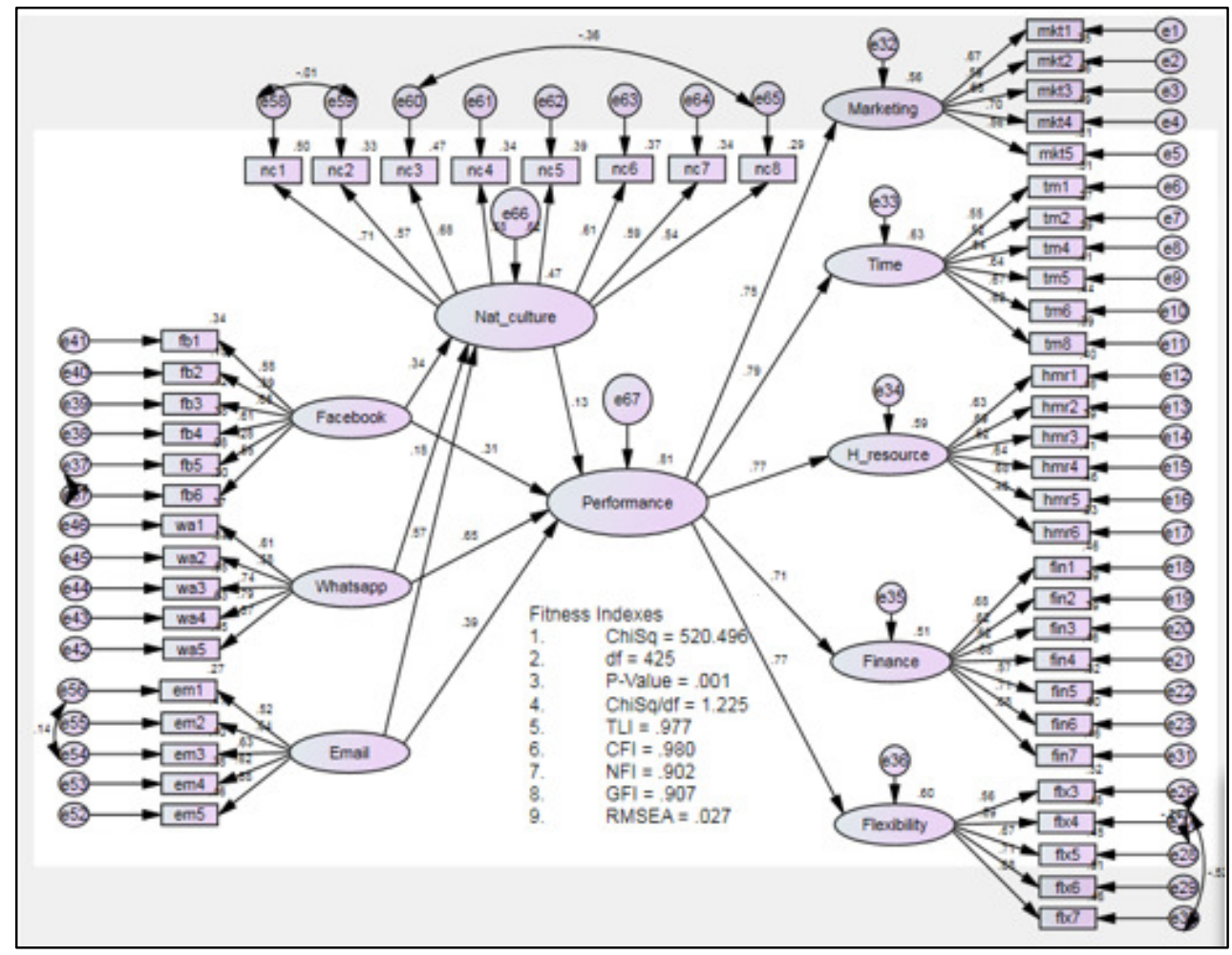

Figure 4: Final structural model

Table 6 shows a summary of the fitness indexes obtained from the initial and final structural model. The analysis indicated that the final model satisfied all the necessary requirements for model acceptance.

Table 6: Fitness indexes for structural models

\begin{tabular}{|c|c|c|c|c|c|c|}
\hline Category & $\begin{array}{l}\text { Parsimonious } \\
\text { fit }\end{array}$ & $\begin{array}{l}\text { Absolute } \\
\text { fit }\end{array}$ & $\begin{array}{l}\text { Incremental } \\
\text { fit }\end{array}$ & $\begin{array}{l}\text { Incremental } \\
\text { fit }\end{array}$ & $\begin{array}{l}\text { Absolute } \\
\text { fit }\end{array}$ & Comment \\
\hline $\begin{array}{l}\text { Fitness } \\
\text { Indexes }\end{array}$ & Chisq/df & GFI & CFI & NFI & RMSEA & \\
\hline $\begin{array}{l}\text { Acceptance } \\
\text { Threshold }\end{array}$ & Chisq/df $\leq 30$ & $\mathrm{GFI} \geq .90$ & $\mathrm{CFI} \geq .90$ & $\mathrm{NFI} \geq .90$ & $\begin{array}{l}\text { RMSEA } \leq \\
.08\end{array}$ & \\
\hline $\begin{array}{l}\text { Initial } \\
\text { Structural } \\
\text { Model }\end{array}$ & 3.128 & $\mathrm{Na}$ & .598 & .507 & .093 & $\begin{array}{l}\text { Fitness } \\
\text { level not } \\
\text { achieved; } \\
\text { model not } \\
\text { accepted }\end{array}$ \\
\hline $\begin{array}{l}\text { Final } \\
\text { Structural } \\
\text { Model }\end{array}$ & 1.225 & .907 & .980 & .902 & .027 & $\begin{array}{l}\text { Fitness } \\
\text { level } \\
\text { achieved; } \\
\text { model } \\
\text { accepted }\end{array}$ \\
\hline
\end{tabular}




\section{Evaluation of Direct Relationships}

The structural path for the relations between the exogenous and endogenous constructs is presented in Table 7 . The table shows the direct relationships between SME Performance and the four exogenous constructs. The standardized regression weight for the path indicated that only one of the path coefficients was non-statistically significant. Thus, the paths reported the following statistics: Performance $\leftarrow$ National culture $(\beta=.130 ;$ C.R. $=1.458 ; \mathrm{p}=.145)$; Performance $\leftarrow$ Facebook $(\beta=.315$; C.R. $=$ 3.585; $\mathrm{p}<.05)$; Performance $\leftarrow$ WhatsApp $(\beta=.654 ;$ C.R. $=6.158 ; p<.05)$, Performance $\leftarrow$ Email $(\beta=.385$; C.R. = 3.935; $\mathrm{p}<.05$ ) which collectively explained about 81 percent variation in SME Performance.

Similarly, the path coefficients for the relations between the endogenous construct, national culture and the three exogenous constructs (Facebook, whatsApp and email) Nat_culture $\leftarrow$ Facebook indicated a statically significant relationship with the following path statistics: $(\beta=.342$; $\mathrm{p}<.05)$; Nat_culture $\leftarrow$ WhatsApp $(\beta=.176$; C.R. = 2.665; p < .05), and Nat_culture $\leftarrow$ Email $(\beta=.567 ;$ C.R. $=6.400 ; p$ $<.05)$. The three exogenous constructs collectively explained about 56 variation in national culture.

Table 7: Standardized regression weight of the path relationship

\begin{tabular}{|c|c|c|c|c|c|}
\hline Path relationship & Estimate & S.E. & C.R. & P-value & $\mathbf{R}^{2}$ \\
\hline $\begin{array}{l}\text { Performance } \leftarrow \text { National } \\
\text { culture }\end{array}$ & .130 & .055 & 1.458 & .145 & \multirow{4}{*}{.81} \\
\hline Performance $\leftarrow$ Facebook & .315 & .157 & 3.585 & $* * *$ & \\
\hline Performance $\leftarrow$ WhatsApp & .654 & .073 & 6.158 & $* * *$ & \\
\hline Performance $\leftarrow$ Email & .385 & .060 & 3.935 & $* * *$ & \\
\hline Nat_culture $\leftarrow$ Facebook & .342 & - & - & $* * *$ & \multirow{3}{*}{.56} \\
\hline Nat_culture $\leftarrow$ WhatsApp & .176 & .074 & 2.665 & .008 & \\
\hline Nat_culture $\leftarrow$ Email & .567 & .089 & 6.400 & $* * *$ & \\
\hline
\end{tabular}

${ }^{* * *}$ indicates significance at $p<.05$

\section{Evaluation of Indirect Relationship}

The research theoretical framework depicts an indirect relation between the exogenous constructs (Facebook, WhatsApp, and email) and the endogenous construct (SME Performance) with national culture acting as a mediator construct. This suggests the need for testing the indirect effect of the exogenous constructs on the endogenous construct via the national culture.

To test the mediation effect, the bootstrapping method was used. Hayes (2014) described the bootstrapping method as the most effective method for testing mediation in SEM analysis. The procedure involved re-sampling of the working data set between 500 and 1000 times to create a sampling distribution from which the total effect, the direct effect and indirect effect estimates and their corresponding 95 percent confidence interval values, are produced. The algorithm also estimates the lower and upper limits as well as the twotailed significant values for the effects.

Table 8 shows the bootstrapping result for testing the mediation effect of national culture in the research model. As shown in the table, the standardized indirect (mediated) effect of Facebook on Performance is significantly different from zero at the 0.001 level ( $p=.200$ two-tailed). Similarly, the standardized indirect (mediated) effect of WhatsApp on Performance is significantly different from zero at the 0.001 level ( $p=.309$ two-tailed). Likewise, the standardized indirect (mediated) effect of Email on Performance is significantly different from zero at the 0.001 level ( $p=.200$ two-tailed). 
Table 8: Two-tailed significance of bootstrap confidence interval for indirect effect

\begin{tabular}{|l|l|l|l|l|}
\hline \multicolumn{1}{|c|}{ Path relationship } & Estimate & \multicolumn{1}{|c|}{$\begin{array}{c}\text { Lower } \\
\text { Bounds }\end{array}$} & Upper Bounds & P-value \\
\hline $\begin{array}{l}\text { Performance } \leftarrow \text { Nat. } \\
\text { Culture } \leftarrow \text { Facebook }\end{array}$ & .044 & -.045 & .155 & .200 \\
\hline $\begin{array}{l}\text { Performance } \leftarrow \text { Nat. } \\
\text { Culture } \leftarrow \text { WhatsApp }\end{array}$ & .023 & -.020 & .102 & .309 \\
\hline Performance $\leftarrow$ Nat. Culture $\leftarrow$ Email & .074 & -.070 & .215 & .200 \\
\hline
\end{tabular}

\section{Limitations of the Study}

As a norm with all studies, this study faced several limitations. If these limitations are addressed in a proper manner in future work, they could result in an improvement of results with better overall quality and findings.

This limitation was observed based on insufficient literature on the relations between the components of the variables. The researcher was limited in having a detailed discussion on social media marketing tolls based on various perspectives with the scarcity of past research materials. Time and budget were also obstacles to conduct the study with larger sample size and on more than one industry.

However, the limitations of the study provide avenues for future research. A significant limitation was felt in the process of collecting data. Firstly, since the target population in this study is SMEs in UAE, gaining access to the right department and employees of the SMEs in UAE turned out to be an arduous task. In addition, given the nature of the questionnaire which touches on areas of social media marketing, privacy of the respondent was of utmost importance. In future, it is suggested that the model be utilized in various sections of the SMEs to prevent the difficulty of collecting data and to assist in expanding the findings.

\section{Recommendations for Future Research}

The researcher recommends the following steps for future work in this area. The limitations in this study are expected to be addressed in future studies. Therefore, the researcher recommends that a wider scope with more detailed questions are developed and utilized. Future studies can narrow the study's scope to certain criteria to prevent biased responses. In future, the questionnaires should also be distributed to more people in order to improve the findings of the survey. The researcher recommends the following for future work in this area.

The sample area and size should be widened by including companies out of SMEs in UAE. This would help to lower the case of bias and help in improving the accuracy of the findings.

The variables should be increased. The variables used in future studies could be increased to include variables that are not included so that the scope could be widened. It is suggested that, future research work should be as a comparative study between different countries, this could undoubtedly increase the cope and provide more understanding of social media marketing by many organizations in different countries.

\section{Conclusion}

This research is on the impact of social media marketing and e-commerce on the performance of SMEs in UAE: A structural equation modelling. The research paper investigates the social media marketing impact on SMEs performance. Data were collected from the SMEs in UAE. The research employed quantitative approach and used questionnaire to collect relevant data from the respondents. The model was developed using SPSS and AMOS software as the research is quantitative in nature. 


\section{References}

- $\quad$ Abalaesei, M. (2015). The Influence of Culture on the Role of Social Media in Decision Making. Discourse as a Form of Multiculturalism in Literature and Communication - Social Sciences, June 2012, 600-612.

- Abu Bakar, A. R., Ahmad, S. Z., \& Ahmad, N. (2019). SME social media use: A study of predictive factors in the United Arab Emirates. Global Business and Organizational Excellence, 38(5), 53-68.

- Ahmad, S. Z., Bakar, A. R. A., \& Ahmad, N. (2019). Social media adoption and its impact on firm performance: the case of the UAE. International Journal of Entrepreneurial Behavior \& Research.

- Al Tawara, A., \& Gide, E. (2017). A Comprehensive Literature Review on the Adoption of Social Media Marketing in SME Retailors in Jordan. International Journal of Business and Management Studies, ISSN, 21581479.

- $\quad$ AlSharji, A., Ahmad, S. Z., \& Bakar, A. R. A. (2018). Understanding social media adoption in SMEs.Journal of Entrepreneurship in Emerging Economies.

- Assimakopoulos, C., Antoniadis, I., Kayas, O. G., \& Dvizac, D. (2017). Effective social media marketing strategy: Facebook as an opportunity for universities. International Journal of Retail \& Distribution Management.

- Basri, W. (2016). Social media impact on small and medium enterprise: Case review of businesses in the arab world. Arts and Social Science Journal, 7(6), 236.

- $\quad$ Basri, W. S. M., \& Siam, M. R. (2019). Social media and corporate communication antecedents of SME sustainability performance. Journal of Economic and Administrative Sciences.

- Bellucci, M., \& Manetti, G. (2017). Facebook as a tool for supporting dialogic accounting? Evidence from large philanthropic foundations in the United States. Accounting, Auditing \& Accountability Journal.Business Review, 26(2), 106-121.

- Chugh, R., \& Ruhi, U. (2018). Social media in higher education: A literature review of Facebook. Education and Information Technologies, 23(2), 605616.

- Dar, Q. A., Ahmad, F., Ramzan, M., Khan, S. H., Ramzan, K., Ahmed, W., \& Kamal, Z. (2017). Use of social media tool "Whatsapp" in medical education. Annals of King Edward Medical University, 23(1).

- $\quad$ Davis, M. H. (2018). Empathy: A social psychological approach. Routledge.

- Galati, A., Crescimanno, M., Tinervia, S., \& Fagnani, F. (2017). Social media as a strategic marketing tool in the Sicilian wine industry: Evidence from Facebook. Wine Economics and Policy, 6(1), 40-47.

- Hair, J. F., Hult, G. T., Ringle, C., \& Sarstedt, M. (2014). A Primer on Partial Least Squares Structural Equation Modeling (PLS-SEM)

- Hair, J. F., Sarstedt, M., Hopkins, L., \& Kuppelwieser, V. G. (2014). Partial least squares structural equation modeling (PLS-SEM): An emerging tool in business research. European

- Hair, J., Black, W. C., Babin, B. J., \& Anderson, R. E. (2010). Multivariate data analysis: A global perspective. Basim, Pearson Education Inc.

- Hofstede, G. (1980). Motivation, leadership, and organization: do American theories apply abroad? Organizational dynamics, 9(1), 42-63.

- Iqbal, A. (2018). Use of Social Media to Promote National Culture 978-5-79962231-2 090. October 2017.

- $\quad$ Khatun, A., \& Al-Dhlan, K. A. (2017). Effectiveness of WhatsApp: A Social Media Tool for Student's Activities in Saudi Arabia. International Journal of Technology and Educational Marketing (IJTEM), 7(2), 17-23.

- Makki, E., \& Chang, L. C. (2015). Understanding the effects of social media and mobile usage on ecommerce: an exploratory study in Saudi Arabia. International management review, 11(2), 98.

- Minkov, M., \& Hofstede, G. (2012). Is National Culture a Meaningful Concept? Cultural Values Delineate Homogeneous National Clusters of InCountry Regions. Cross-Cultural 
Research, 46(2), 133-159. https://doi.org/10.1177/1069397111 427262

- Nuseir, M. T. (2018). Digital media impact on SMEs performance in the UAE. Academy of Entrepreneurship Journal.

- Odoom, R., \& Mensah, P. (2018). Brand orientation and brand performance in SMEs: The moderating effects of social media and innovation capabilities.

- Olanrewaju, A. S. T., Hossain, M. A., Whiteside, N., \& Mercieca, P. (2020). Social media and entrepreneurship research: A literature review. International Journal of Information Management, 50, 90-110.

- $\quad$ Salloum, S. A., Al-Emran, M., Monem, A. A., \& Shaalan, K. (2017). A survey of text mining in social media: facebook and twitter perspectives. Adv. Sci. Technol. Eng. Syst. J, 2(1), 127-133.

- Sheldon, P., Herzfeldt, E., \& Rauschnabel, P. A. (2020). Culture and social media: the relationship between cultural values and hashtagging styles.

Behaviour and Information

Technology, 39(7), 758-770.

https://doi.org/10.1080/0144929X.20 19.1611923.

- Sinkala, E., Sollier-Christen, E., Renier, C., Rosas-Canyelles, E., Che, J., Heirich, K., \& Jeffrey, S. S. (2017). Profiling protein expression in circulating tumour cells using microfluidic western blotting. Nature communications, 8(1), 1-12.

- Sinnenberg, L., Buttenheim, A. M., Padrez, K., Mancheno, C., Ungar, L., \& Merchant, R. M. (2017). Twitter as a tool for health research: a systematic review. American journal of public health, 107(1), e1-e8.

- Zaidan, E. (2017). Analysis of ICT usage patterns, benefits and barriers in tourism SMEs in the Middle Eastern countries: The case of Dubai in UAE. Journal of Vacation Marketing, 23(3), 248-263. 